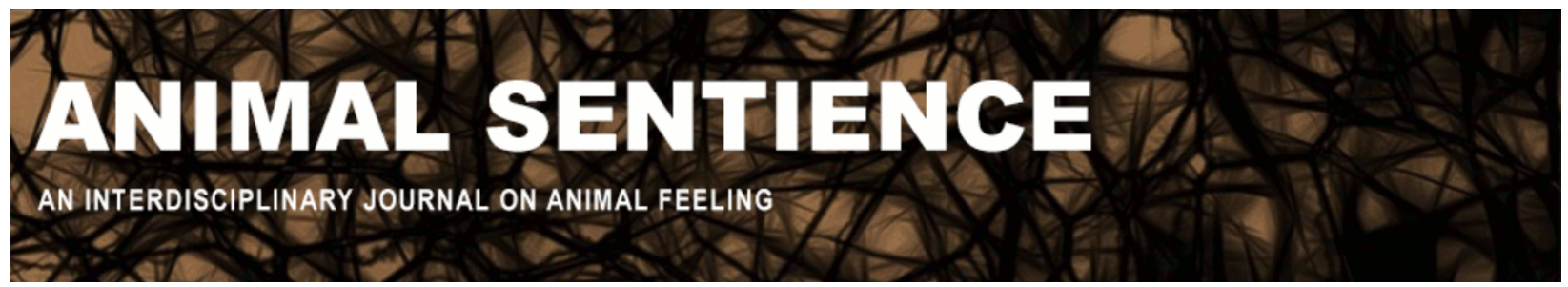

Woodruff, Michael L. (2020) Whether invertebrates are sentient matters to bioethics and science policy. Animal Sentience 29(16)

DOI: $10.51291 / 2377-7478.1600$

Date of submission: $2020-06-25$

Date of acceptance: 2020-06-29

(c)

This article has appeared in the journal Animal

Sentience, a peer-reviewed journal on animal

cognition and feeling. It has been made open access,

free for all, by WellBeing International and deposited

in the WBI Studies Repository. For more information,

please contact

wbisr-info@wellbeingintl.org.

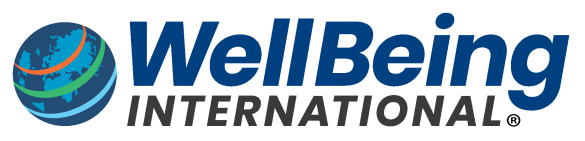

SOLUTIONS FOR PEOPLE, ANIMALS AND ENVIRONMENT 


\title{
Whether invertebrates are sentient matters to bioethics and science policy
}

Commentary on Mikhalevich \& Powell on Invertebrate Minds

\author{
Michael L. Woodruff \\ Biomedical Sciences, East Tennessee State University
}

\begin{abstract}
Mikhalevich \& Powell provide convincing empirical evidence that at least some invertebrates are sentient and hence should be granted moral status. I agree and argue that functional markers should be the primary indicators of sentience. Neuroanatomical homologies provide only secondary evidence. Consensus regarding the validity of these functional markers will be difficult to achieve. To be effective in practice, functional markers of sentience will have to be tested and accepted species by species to overcome the implicit biases against extending moral status to invertebrates.
\end{abstract}

Michael L. Woodruff is Professor Emeritus of Biomedical Sciences in the Quillen College of Medicine at East Tennessee State University. His current research interests include cognitive neuroscience and the philosophy of mind. Website

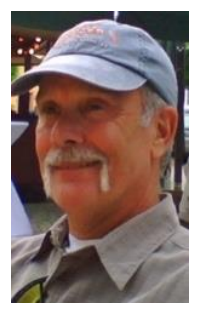

Mikhalevich \& Powell (2020) (M\&P) argue convincingly that there is no empirically valid reason to deny "certain invertebrates" the moral standing afforded to nonhuman vertebrates by bioethics and science policy on the basis of comparable data. In the tradition of ethicists from Jeremy Bentham (1780/2019) in the $18^{\text {th }}$ century to Peter Singer $(1975)$ in the $20^{\text {th }}$, M\&P invoke sentience as the touchstone for according moral status; they review the compelling evidence that at least some invertebrates are sentient.

I would define sentience as the minimal capacity for direct subjective experience of the qualities associated with sensations, including accompanying affective states. Sentient beings, therefore, have the ability to feel an experience, and this feel will have some "valence" associated with it; in the simplest context, the experience may be either good or bad. As M\&P note, the focus of bioethics and science policy governing the use of animals in research has followed Bentham's emphasis on the prevention of bad experiences, particularly pain and suffering. For example, detailed protocols are in place regarding the use of specific anesthetics and analgesics during and after surgery in experimental vertebrate animals.

In addition to the moral obligation to avoid creating pain "broadly construed" in animal subjects, M\&P also clearly articulate our moral obligation to "provide positive conditions in which sentient animals can flourish - environments in which they can experience greater amounts of pleasure and develop their natural range of abilities." This is a valid philosophical position, but the practical complexity of determining what constitutes pleasure and flourishing in nonverbal animals makes it even more complicated to resolve the fundamental problem discussed extensively by M\&P: determining whether nonverbal animals are sentient at all. 
Achieving a consensus solution on sentience has already proven elusive, even when the discussion is limited to one specific qualitative sensation - the feeling of pain - and the subjects are vertebrates, such as fishes. Fishes exhibit many flexible and intricate behaviors strongly supporting the inference that they have a high level of cognitive sophistication. Fishes also respond to analgesics in the same way mammals do - convincing support that fishes are sentient and experience pain (Brown 2014, Sneddon 2015, Sneddon et al. 2018).

Some scientists (Key 2016, Rose 2002, Rose et al. 2014) strongly disagree, contending that even the most complex behaviors of fishes are explicable as reflexes and complex species-typical behaviors, and that the effects of analgesics in fishes can be explained not by their ability to block the conscious experience of pain, but solely by their ability to blockade nociception. They argue that the brains of fishes are too simple to support sentience, but research spanning the last three decades indicates that the neuroanatomy of the brains of fishes is remarkably complex and exhibits several of the physiological markers suggested to accompany phenomenal consciousness and the experience of pain in humans (Woodruff 2017, 2018a, b). Although the neuroanatomy of fishes is not homologous with the thalamo - cortical system of mammals - fish brains are capable of functioning in an analogous manner to produce similar behavioral and physiological markers of sentience.

These findings support the position of M\&P, which should emphasize analogy rather than homology. In the biological sciences, structures are defined as homologous across species when they are inherited from a common ancestor. They may or may not have the same function as they did in that ancestor or in members of other descendent species. An independent analysis of the relationship between anatomical structure and metrics such as physiological or behavioral activities must be made before functional analogies can be formulated for homologous structures. Or, as M\&P express it, "homology hypotheses are not function-free and hence have no independent advantages over functional analyses of convergent brains."

Functional markers of mental states, such as sentience, are fundamental. Structural homologies are secondary. Behavioral and physiological activities analogous to those associated with sentience in vertebrates are adequate to establish sentience in invertebrate species regardless of whether their brains are homologous structurally. Achieving consensus on which functional activities are valid markers of mental states has proven difficult even for some vertebrate species; hence reaching a consensus for invertebrates that includes markers for flourishing - a concept far more complex than simply feeling pain - will be still more difficult. Moreover, if the goal is change in public policy, lay policymakers must be meaningfully involved in the discussion. In my own experience, laypersons often find it more difficult than professional scientists and philosophers to substitute rational, evidence-based decision-making for the cognitive-affective biases described by M\&P.

M\&P discuss the Animal Sentience Precautionary Principle (ASPP) proposed by Birch (2017) as a way of generalizing functional observations across an entire order of animal. They note difficulties with the ASPP, including behavioral underdetermination. I agree with this critique and would go further to suggest that overcoming disgust and the empathy gap cannot be realistically approached other than with species-by-species analyses of behavioral activities. This does not eliminate the problem of behavioral underdetermination, but it will make generalizability more convincing because of the similarity of the subjects involved. 
If behaviors that many people accept as indicators of the ability to have positive and negative feelings are identified in an invertebrate species, it will become easier for people to develop empathy for an alien-appearing animal such as the octopus (Mather 2019), and thereby become more concerned about its welfare. This proposal is supported by social psychologists who have discovered that humans who eat meat attribute significantly fewer indicators of sentience to animals that end up on their plate than do vegetarians (Bastian et al. 2012, Bilewiczi et al. 2011, Loughnan et al. 2010).

In conclusion, I have attempted to make the following points. First, in agreement with M\&P, based on inferring sentience from empirical evidence that reveals the flexibility and complexity of their behaviors, moral status should be extended to at least some invertebrates. Second, functional behavioral and physiological markers should be the primary indicators of sentience in invertebrates. Structural neuroanatomical homologies provide only secondary evidence. Third, a consensus that these functional markers are valid indicators of sentience will be difficult to achieve; to be effective in practice, they will have to be provided and accepted on a species-byspecies basis rather than en bloc. Finally, I agree with Levy (2020) that "Much of the work done by appeals to phenomenal consciousness can in fact be done by functionalizable properties of the mind" (p. 2). To overcome the implicit biases against extending moral status to invertebrates, convincing evidence of sentience will be a practical necessity for each species.

\section{References}

Bastian, B., Loughnan, S., Haslam, N., \& Radke, H. R. M. (2012). Don't mind meat? The denial of mind to animals used for human consumption. Personality and Social Psychology Bulletin, $38,247-256$.

Bentham, J. (1780/2019). An Introduction to Principles of Morals and Legislation. Anodos Books, Dumfries and Galloway: Scotland.

Bilewiczi, M., Imhoff, R., \& Drogosz, M. (2011). The humanity of what we eat: Conceptions of human uniqueness among vegetarians and omnivores. European Journal of Social

Psychology, 41, 201-209

Birch, J. (2017). Animal sentience and the precautionary principle. Animal Sentience 16(1).

Brown, C. (2014). Fish intelligence, sentience and ethics. Animal Cognition, 18, 1-17.

Levy, N. (2020). It might not matter very much whether insects are conscious. Animal

Sentience 29(2).

Loughnan, S., Haslam, N.,Murnane, T., Vaes, J., Reynolds, C., \& Suitner, C. (2010). Objectification leads to depersonalization: The denial of mind and moral concern to objectified others.

European Journal of Social Psychology, 40, 709-717.

Mather, J. (2019). What is in an octopus's mind? Animal Sentience 26(1).

Mikhalevich, I., \& Powell, R. (2020). Minds without spines: Evolutionarily inclusive animal ethics. Animal Sentience 29(1).

Rose, J. D. (2002). The neurobehavioral nature of fishes and the question of awareness and pain. Reviews in Fisheries Science, 10, 1-38.

Rose, J. D., Arlinghaus, R., Cooke, S. J., Diggles, B. K., Sawynok, W., Stevens, E. D., \& Wynne, C. D. L. (2014). Can fish really feel pain? Fish and Fisheries, 15, 97-133. 
Singer, P. (1975). Animal Liberation: A New Ethics for our Treatment of Animals. HarperCollins. Sneddon, L. U. (2015). Pain in aquatic animals. Journal of Experimental Biology, 218, 967-976.

Sneddon, L. U., Lopez-Luna, J., Wolfenden, D. C. C.., Leach, M. C., Valentim, A. M., Steenbergen, P. J., Bardine, N., Currie, A. D., Broom, D. M., \& Brown, C. (2018). Fish sentience denial: Muddying the waters. Animal Sentience 21(1).

Woodruff, M. L. (2017). Consciousness in teleosts: There is something it feels like to be a fish. Animal Sentience 13(1).

Woodruff, M. L. (2018a). Pain in fish: Evidence from peripheral nociceptors to pallial processing. Animal Sentience 21(2).

Woodruff, M. L. (2018b). The fish in the creek is sentient, even if I can't speak with it. Trans/Form/Ação, 41(Edição Especial), 119-152. 